\title{
The digital black market and drugs: do you know where your children are?
}

\section{Opinion}

Parents, do you know where your children are? The public service announcement (PSA) of our youth takes on a whole new meaning in the era of the Internet. ${ }^{1}$ Our children are often right there, in our own homes doing the very things we want to protect them from-and we know exactly where they are - but we don't know what they are doing. ${ }^{2}$ We don't even know what they could be doing! When was the last time your teen received a package in the mail? These days with amazon, eBay, ${ }^{3}$ and internet commerce, it is commonplace to receive packages in the mail and you may think nothing of it. Read further and you may start checking that packages. ${ }^{4}$

Have you heard of the Darknet? Do you know what cryptocurrency is? Have you ever heard of TOR? These are very compelling reasons for parents to learn and embrace new technology. ${ }^{5}$ If you do not understand it, you may not be able to stop it. These three things are the gateway to the digital black market for drugs, guns, and many other illegal products and services. ${ }^{6}$ The Darknet and the digital black market is accessible through a browser referred to as TOR. The Darknet is the non-indexed, secret section of the Deep Web that is primarily, used by those engaged in illegal activities. ${ }^{7}$ It cannot be accessed through regular browsers. It is a group of websites with onion domains and the Onion Router or Tor browser software is needed to access these sites. This allows for world-wide anonymous web browsing. Once in, there are Google-style search engines and Amazon-style marketplaces selling stolen passports, weapons, hacked account numbers, and drugs lots and lots of drugs. You may have been hearing about the Bitcoin rage. ${ }^{8}$ But what you need to realize is that bitcoin is a cryptocurrency. ${ }^{9}$ Cryptocurrencies are not traceable, and were developed to protect anonymity. ${ }^{10}$ Why? So the new wave of black market dealers can sell their products and services online, without being traced. ${ }^{11}$ While the Darknet is full of all kinds of illicit activities, our teens are using it to buy drugs. ${ }^{12,13}$

It may seem outrageous to believe that your child can get heroin, fentanyl, or oxycontin shipped right to your doorstep without notice. TOR, the Dark web, and Bitcoin make this possible. ${ }^{14}$ Buyers and sellers make contact using e-mail providers such as Sigaint, a secure dark-web email service, and encryption software like Pretty Good Privacy (PGP). It's a whole new world-and many parents are left in the dust because technology keeps moving and we do not. ${ }^{15}$

Today's dealers are tech-savvy and so are our teens. Most teens know more about the internet than we do and they will explore, experiment, and even rebel in ways we never imagined possible. ${ }^{16}$ Explorers may be enticed at first, with free samples or substances deemed legal, safe, and undetectable - like the once widely legal, herbal opiod, Kratom-and the addiction, or worse, has its beginning. Kratom has become majorly popular among teens, and they are often introduced to it through the Darknet. Recently, Scott Gottlieb, commissioner of the Food and Drug Administration, issued a public health advisory on Kratom, suggesting that all states ban this synthetic opioid. ${ }^{17}$

\author{
Volume 5 Issue 6 - 2018 \\ Melissa Vayda \\ Educational Affairs Penn State College of Medicine, University \\ Park, USA
}

Correspondence: Melissa Vayda, Director, Educational Affairs Penn State College of Medicine, University Park, USA, Emailmelissawayda@gmail.com

Received: March 12, 2018| Published: November 15, 2018

Unfortunately, this is just the tip of the iceberg where drugs on the Darknet are concerned. 'Lesser' drugs are often laced with a stringer synthetic opioid, fentanyl, which is the fastest-growing cause of overdoses nationwide. ${ }^{18}$ Just a few flakes of fentanyl can be fatal. When it is not fatal, it feeds an opioid addiction (Figure 1).

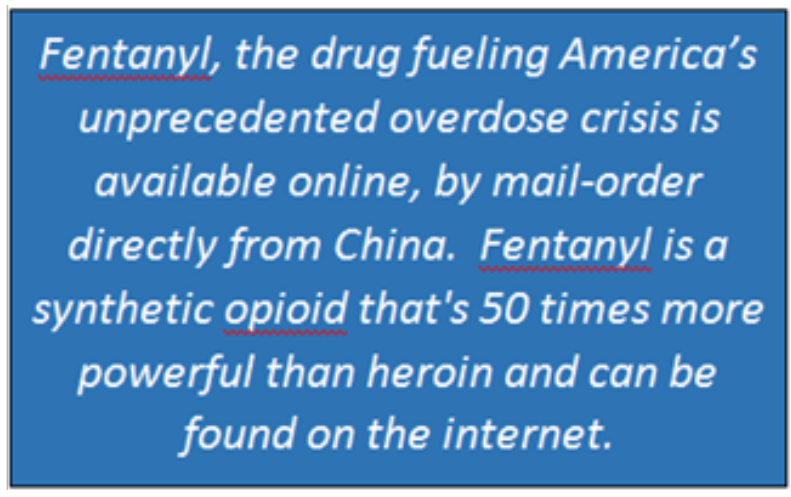

Figure I Drug fueling.

The bottom line is that the internet allows teens to buy drugs easily and receive them unnoticed, and they do this in the comfort of their own homes. ${ }^{19}$ These drugs come from overseas and are often from China, Ukraine, or Mexico. ${ }^{20}$ They can travel international mail undetected, and end up on your doorstep. Very few packages get intercepted. The U.S government is constantly seeking new measures to combat drug sales, but the internet has changed the entire ballgame. ${ }^{21}$ (Figure 2)

Drug trafficking is not a new problem, just a more sophisticated one today. ${ }^{22}$ Founded in 2011, Silk Road was the most popular Darknet (black) market, until it was brought down by the DEA, Homeland Security and the FBI in 2013..$^{23,24}$

The founder who yielded over $\$ 1.2$ billion in sales in less than 3 years, was charged with engaging in a continuing criminal enterprise, narcotics trafficking, money laundering, and computer hacking. He is now in prison for life. ${ }^{25}$ This was followed by the recent takedown of AlphaBay marketplace, said to be ten times bigger than Silk Road. ${ }^{26}$ 
The Agora Marketplace is yet another drug sales location on the Darknet. One site goes down, and five more pop up. It is a daunting regulation task for any government. Just yesterday, ${ }^{27}$ the Department of Justice announced the creation of the Joint Criminal Opioid Darknet Enforcement team or J-CODE, to target the disruption of Darknet drug sales and the destruction of criminal enterprises facilitating trafficking. Figure 3

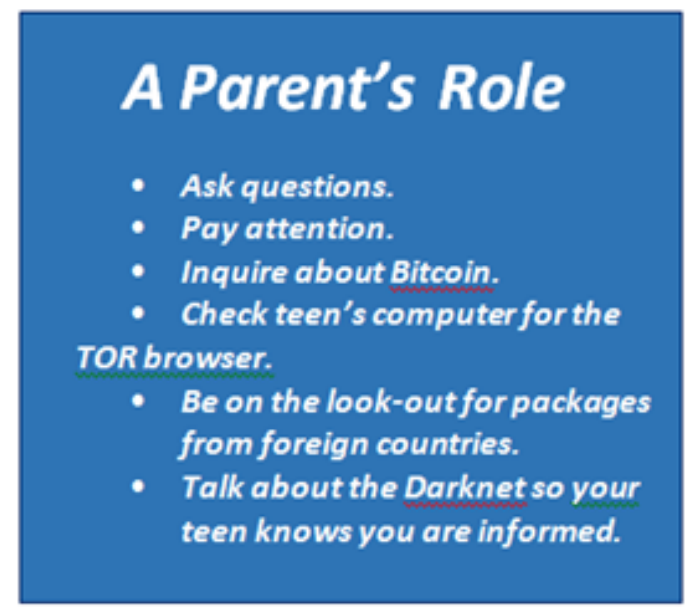

Figure 2 A parent's role.

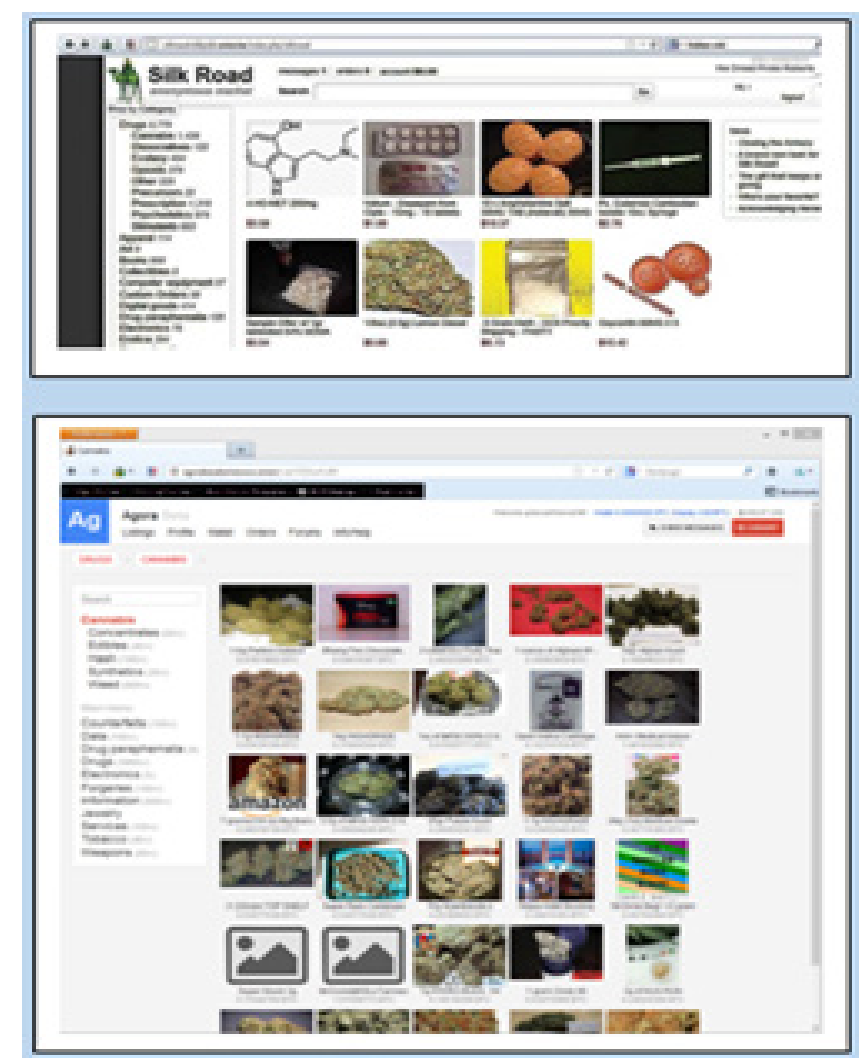

Figure 3 Sample darknet marketplace sites.

Although some black market dealers get caught, the Darknet continues to grow and get more sophisticated. The Darknet has revolutionized the drug trade..$^{28}$ It is no longer a seedy exchange in a dark alley-it's as easy as buying something on amazon and waiting for it to get delivered by the mailman. This is what we know; deaths from synthetic opioids (fentanyl, carfentanil) have surpassed deaths related to heroin and common prescription opioids such as morphine. Overdose deaths among ages 15-19 have risen 23\% between 20152017. ${ }^{29}$ The fastest growing segment of the Darknet drug sales is synthetic opioids. Teens know how to navigate technology.

Parents need to stay in touch with technology and their teens to play a part in monitoring exposure to black market drugs.

\section{Acknowledgements}

None.

\section{Conflict of interest}

The author declares no conflict of interest.

\section{References}

1. Allen Hoffmann. Before Dark Net Markets Were Mainstream. 2015.

2. Monica Barratt. A Discussion About Dark Net Terminology. Drugs, Internet, Society. 2015.

3. Bartlett J. Dark net markets: the eBay of drug dealing. 2014.

4. Mike Power. Online highs are old as the net: the first e-commerce was a drugs deal. 2013.

5. Deep Dot Web. Updated: List of Dark Net Markets (Tor \& I2P). 2018.

6. Plenke M. Inside the Underground Market Where Bodybuilders Find Dangerous, Illegal Steroids. 2015.

7. Paganini P. The Deep Web and Its Darknets. 2015.

8. Power M. Drugs 2.0. ISBN 9781846274619.

9. Van Hardeveld G. Deviating From the Cybercriminal Script: Exploring Tools of Anonymity (Mis) Used by Carders on Cryptomarkets. 2017.

10. Torpey Kyle. Blockchain.info Launches Tor Hidden Service. Inside Bitcoins. 2018.

11. Roger J. Clearnet vs Hidden Services-Why You Should Be Careful. Jolly Roger's Security Guide for Beginners. Deep Dot Web.

12. NPR Staff. Going Dark: The Internet Behind The Internet. 2014.

13. Gayle D. Online market 'is turning drug dealers from goons to geeks. 2016.

14. Ward M. Tor's most visited hidden sites host child abuse images. 2014.

15. Greenberg A. It's About to Get Easier to Hide on the Dark Web. Wired. 2017;78-83.

16. Whitaker R. Why I Had to Buy My Wife's Inhaler on the Dark Web. 2015.

17. Wing N. Feds Prepare For A New War On Kratom. 2017.

18. Winder D. Is this new zero-day dark market the real deal? 2015.

19. Compton W. House Committee on Energy and Commerce, Subcommittee on Oversight and Investigations: Darknet Commerce. 2017.

20. Cyber Security Dojo. Romania defending Ukraine's cyberspace. 2015.

21. Popperjune, Nathaniel. Steven Thrasher Teen drug overdose rate in US rose $20 \%$ in 2015. The Guardian. 2017;A1-A3. 
22. Howell O'Neill P. The uncensored history of the Internet's drug revolution. 2015.

23. Hong N. Silk Road Creator Found Guilty of Cybercrimes. Wall Street Journal. 2015;A1-A4.

24. Weiser B. Man Behind Silk Road Website Is Convicted on All Counts. New York Times. 2015

25. Howell O'Neill Pk. How the Internet powered a DIY drug revolution. 2013.
26. Leswing K. The FBI just took down AlphaBay, an online black market for drugs that was 10 times bigger than Silk Road. 2017.

27. Bennett Cory. Private 'darknet' markets under siege. 2017.

28. Ingelvaldson D. What's Lurking in the Deep End of the Internet. Wired. 2015;88-95.

29. Lardieri A. Report: Alcohol, Drug, Suicide Deaths Hit New High. 2018. 